\title{
Epidermal growth factor receptor inhibition strategies in oncology
}

\author{
P M Harari
}

University of Wisconsin Medical School, Department of Human Oncology, University of Wisconsin Medical School, 600 Highland Avenue K4/332, Madison, Wisconsin 53792, USA

(Requests for offprints should be addressed to P M Harari; Email: harari@humonc.wisc.edu)

\begin{abstract}
Molecular targeting strategies for cancer therapy are distinct from conventional chemotherapy and radiotherapy in their potential to provide increased tumor specificity. One particular molecular target of high promise in oncology is the epidermal growth factor receptor (EGFR). The EGFR is overexpressed, dysregulated or mutated in many epithelial malignancies, and EGFR activation appears important in tumor growth and progression. Advances in signal transduction biology continue to sharpen our understanding regarding specific contributions of EGFR signaling networks to cancer behavior. Two predominant classes of EGFR inhibitors have been developed including monoclonal antibodies (mAbs) that target the extracellular domain of EGFR, such as cetuximab (Erbitux), and small molecule tyrosine kinase inhibitors (TKIs) that target the receptor catalytic domain of EGFR, such as gefitinib (Iressa) and erlotinib (Tarceva).

Mechanisms of action for EGFR inhibitors have been investigated in preclinical model systems. Safety, activity, pharmacokinetics and pharmacodynamics have been assessed in clinical trials. The anti-EGFR mAbs and TKIs have partially overlapping toxicity profiles, but distinct routes of administration, serum half-lives and therefore dosing schedules. Both classes of agents show clear antitumor activity, and cetuximab and gefitinib have been recently FDA approved for colorectal and lung cancer indications respectively. However, the absence of survival benefit for EGFR TKIs in combination with chemotherapy in large-scale phase III lung cancer trials in 2003 underscores a major challenge in anti-EGFR oncology therapeutics; namely to identify those tumors and patients that will respond predictably to EGFR inhibitor approaches. Newly identified mutations in the EGFR catalytic domain that appear to confer sensitivity to EGFR TKIs promise to open new doors of investigation regarding response prediction. Advances will also require enhanced molecular understanding of the overall EGFR signaling network, and improved methods to gauge the dependence of individual tumors on EGFR signaling pathways for growth advantage. Results from newly reported phase III trials in 2004 now confirm a survival advantage for the use of EGFR inhibitors in combination with high-dose radiation in head and neck cancer, and in refractory lung cancer respectively. It appears likely that EGFR inhibitors (and other rationally designed molecular growth inhibitors) will play a meaningful role in cancer therapy in the years to come.
\end{abstract}

Endocrine-Related Cancer (2004) 11 689-708

\section{Introduction}

Considerable progress has been made over the last several decades in understanding specific cellular, molecular and genetic mechanisms that contribute to cancer growth and progression. This improved mechanistic understanding of cancer has fostered the design, development, and clinical evaluation of more tumor-specific anticancer treatment approaches.
This review focuses on one particularly promising anticancer treatment strategy, namely that of epidermal growth factor receptor (EGFR) signaling inhibition. The most clinically advanced approach to EGFR inhibition includes the use of monoclonal antibodies (mAbs) directed against the EGFR extracellular domain, and the use of small molecule tyrosine kinase inhibitors (TKIs) directed against the tyrosine kinase domain. The mAbs 


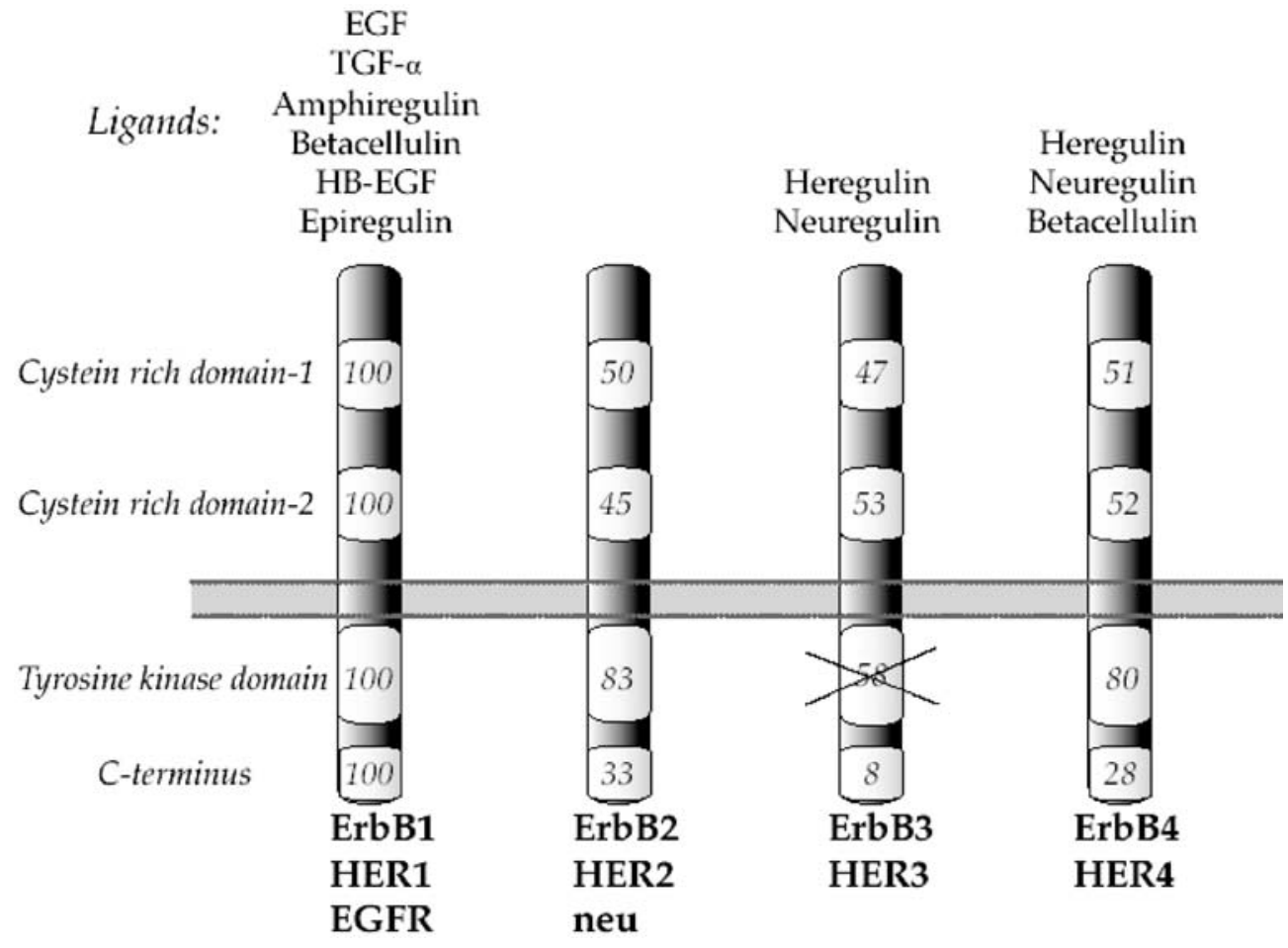

Figure 1 Schematic diagram of the four ErbB family members and their ligands. Numbers denote the degree (expressed as a percentage) of homology relative to ErbB1/EGFR. With the exception of the kinase-deficient ErbB3, there exists a high degree of homology in the tyrosine kinase domain. Adapted with permission from Harari et al. (2003).

function at the extracellular ligand-binding site of the receptor, whereas the small molecule TKIs function at the intracellular tyrosine kinase domain of the EGFR.

\section{EGFR structure and function}

Growth factors and their transmembrane receptor kinases play important roles in cell proliferation, survival, adhesion, migration and differentiation (Yarden 2001). The EGFR family consists of four transmembrane receptors, including EGFR (HER1/erbB-1), HER2 (erbB-2/neu), HER3 (erbB-3) and HER4 (erbB-4) (Yarden 2001). The EGFR (HER1/erbB-1) is a $170 \mathrm{kDa}$ protein comprising three major functional domains: an extracellular ligand-binding domain, a hydrophobic transmembrane domain and a cytoplasmic tyrosine kinase domain, as illustrated in Fig. 1.

Seven genetically distinct ligands - EGF, transforming growth factor- $\alpha(\mathrm{TGF}-\alpha)$, heparin-binding EGF, amphiregulin, betacellulin, epiregulin and neuregulin G2 $\beta$ - have been shown to be capable of binding with EGFR (Watanabe et al. 1994, Toyoda et al. 1997, Wells 1999). Cognate ligand binding triggers erbB receptor aggregation, the formation of receptor homodimers and/ or heterodimers, and internalization (Yarden 2001, Wiley
2003). Dimer formation leads to activation of the intrinsic receptor tyrosine kinase domain. Protein phosphorylation and dephosphorylation, catalyzed by protein kinases (such as tyrosine kinase) and protein phosphatases respectively, represent fundamental biochemical events for subsequent intracellular signal transduction $(\mathrm{Qu}$ 2002). Autophosphorylation of tyrosine residues within the C-terminal tail of EGFR in the cytoplasm (Cohen 2003) following EGFR tyrosine kinase activation initiates a cascade of intracellular signaling pathways (Carpenter $\&$ Cohen 1990). The receptor tyrosine kinase signal can be terminated by endocytosis of the phosphorylated receptor-ligand complex (Yarden 2001).

The EGFR downstream intracellular signal transduction pathways include components of the Ras/mitogenactivated protein kinase (MAPK), phosphatidyl inositol 3-kinase, signal transducer and activator of transcription, downstream protein kinase $\mathrm{C}$ and phospholipase $\mathrm{D}$ pathways (Wells 1999, Carpenter 2000, Grant et al. 2002). Some of these pathways serve to attenuate receptor signaling (Wells 1999). Figure 2 is a simplified schematic illustrating the interaction of the EGFR system and the Ras/MAPK cascade, one of the major signaling routes (Alroy \& Yarden 1997), and its downstream effects on the cell-cycle machinery. Yarden \& Sliwkowski (2001) pro- 




Figure 2 Simplified schematic illustration of the EGFR pathway highlighting potential downstream cellular and tissue effects of EGFR signaling inhibition. The action site for EGFR inhibitors is depicted for mAbs and TKIs. Adapted with permission from Harari \& Huang (2001).

vide a comprehensive description of ErbB signaling pathways. The integrated biological responses to EGFR signaling are pleiotropic. They include mitogenesis, apoptosis, altered cellular motility, protein secretion and differentiation or dedifferentiation (Wells 1999).

\section{EGFR - significance in oncology}

Activation of the EGFR stimulates tumor growth and progression, including the promotion of proliferation, angiogenesis, invasion, metastasis and inhibition of apoptosis (Salomon et al. 1995, Wells 1999, Woodburn 1999). EGFR is normally widely expressed by many cell types, including those of epithelial and mesenchymal lineages (Wells 1999). However, there is variability regarding the reported incidence of overexpression or dysregulation of EGFR in human malignancies (Nicholson et al. 2001, Arteaga 2002). For example, some reports describe EGFR expression as being dysregulated in at least $50 \%$ of human epithelial tumors (Aaronson 1991, Earp et al. 2003, Grunwald \& Hidalgo 2003a), while more conservative estimates suggest that one-third of epithelial malignancies express high levels of EGFR (Mendelsohn 2001). This variability may be partially attributable to a lack of standardization in quantitation methodology, using either using simple immunohistochemistry or more sophisticated fluorescence in situ hybridization techniques. Overall, it does appear that many of our most common human epithelial cancers richly express the EGFR.

In head and neck cancer, the vast majority of tumors are strongly EGFR-positive (Mendelsohn 2001). Studies have also reported EGFR overexpression in the following cancers: bladder, brain, breast, cervical, uterine, colon, esophageal, glioma, non-small-cell lung cancer (NSCLC), ovarian, pancreatic and renal cell (Table 1) (Nicholson et al. 2001, Herbst 2002, Mendelsohn \& Baselga 2003). A review of 200 studies (involving $>20000$ patients) was undertaken to determine the prognostic value of increased EGFR expression for reduced recurrence-free or overall survival rates (Nicholson et al. 2001). Of the ten cancer types for which there were adequate data for analysis, the 
Table 1 Percentage of tumors overexpressing EGFR, by tumor type

\begin{tabular}{ll}
\hline Tumor type & Percentage of tumors \\
\hline Bladder & $31-48$ \\
Breast & $14-91$ \\
Cervix/uterus & 90 \\
Colon & $25-77$ \\
Esophagael & $43-89$ \\
Gastric & $4-33$ \\
Glioma & $40-63$ \\
Head and neck & $80-100$ \\
Ovarian & $35-70$ \\
Pancreatic & $30-89$ \\
Prostate & $40-80$ \\
Renal cell & $50-90$ \\
Non-small-cell lung & $40-80$ \\
\hline
\end{tabular}

prognostic value was strong $(70 \%)$ for head and neck, ovarian, cervical, bladder and esophageal cancers; moderate $(52 \%)$ for gastric, breast, endometrial and colorectal tumors; and weak $(30 \%)$ for NSCLC.

Nonetheless, we now know that some patients with high levels of EGFR expression are refractory to EGFR inhibitor treatment, suggesting that mere expression of EGFR is not a robust predictor of response to therapy. Preclinical studies on 60 cell lines of the United States National Cancer Institute Anticancer Drug Screen were performed with a panel of 11 selective erbB inhibitors. Cell lines expressing high levels of EGFR could be divided into two groups, depending on their sensitivity or insensitivity to EGFR inhibitors (Bishop et al. 2002). The level of EGFR expression for the specific tumor appeared to be less important than the degree of activation of EGFR in predicting the response to targeted therapy. Factors affecting activation status include receptor mutation, heterodimerization and increased expression of ligands (Arteaga 2002). Signaling complexity due to interactions among four receptors and ten ligands makes it difficult to definitively measure signaling output for individual human tumors (Earp et al. 2003). The lack of a clear relationship between the level of EGFR expression and the degree of EGFR activation across tumor types complicates simple prediction of clinical effectiveness of targeted therapeutics (Arteaga \& Baselga 2003).

\section{Inhibition of EGFR in cancer Mechanisms of action of EGFR inhibitors}

mAbs directed against EGFR have the following mechanisms of action: (i) extracellular binding; (ii) internalization of receptor-antibody complexes; (iii) inhibition of EGFR signaling pathways; and (iv) potential stimulation of an immunological response.

TKIs directed against EGFR have the following mechanisms of action: (i) intracellular binding; (ii) prevention of tyrosine kinase activation; and (iii) inhibition of EGFR signaling pathways.

The respective sites of action of mAbs and TKIs are illustrated in Fig. 2.

\section{mAb EGFR inhibitors}

Several mAbs directed against EGFR are in various stages of clinical development. These antibodies are listed in Table 2.

\section{Cetuximab}

The most extensively studied of the anti-EGFR mAbs is cetuximab (Erbitux; ImClone Systems), formerly known as IMC-225 or C225, a chimeric mAb designed to specifically inhibit EGFR (Ennis et al. 1991). Cetuximab has been recently approved (February 2004) by the US Food and Drug Administration and the Swiss Medicines Control Agency for the treatment of colorectal cancer that is unresponsive to irinotecan (Camptosar).

The chimeric antibody was developed by combining the variable regions of the precursor mouse antibody (mAb 225) with human immunoglobulin G1 constant regions to reduce the possibility of an antimouse immunological reaction in patients (Herbst \& Shin 2002). Cetuximab is highly specific for EGFR, competing for natural ligand-binding sites and causing receptor internalization and downregulation (Kim et al. 2001). It inhibits the proliferation of a range of human tumor cell

Table 2 EGFR monoclonal antibodies in clinical trials

\begin{tabular}{llll}
\hline Agent & Type & Generic/trade name & Institution \\
\hline IMC-C225 & Chimeric IgG1 & ${ }^{*}$ Cetuximab/Erbitux & ImClone/BMS/Merck KGaA \\
ABX-EGF & Fully human IgG2 & panitumumab & Abgenix/Amgen \\
EMD 72000 & Humanized IgG1 & - & EMD Pharms/Merck KGaA \\
MDX-447 & Humanized, bispecific: EGFR/FcR $\gamma 1$ & HuMab-Mouse & Medarex/Merck KGaA \\
h-R3 & Humanized & TheraCIM & YM Biosciences/CIM \\
Mab 806 & Anti-EGFR VIII & - & Ludwig Institute \\
\hline
\end{tabular}

${ }^{*}$ Approved. 
lines in a dose-dependent manner (Goldstein et al. 1995, Prewett et al. 1996, 1998, 1999, Huang \& Harari 1999, Herbst \& Hong 2002). This inhibition of cell proliferation reflects cell-cycle arrest in the G1 phase and/or an increase in apoptosis (Prewett et al. 1996, Fan et al. 1997, Huang et al. 1999).

The growth inhibitory impact of cetuximab in tumor xenograft models is often more pronounced than that observed in cell culture, suggesting that additional anticancer mechanisms are involved. One such mechanism involves anti-angiogenesis (Huang \& Harari 1999, Mendelsohn 2001). Cetuximab inhibits vascular endothelial growth factor (VEGF) production in epidermoid carcinoma cells, resulting in a reduction in the number of tumor blood vessels (Viloria-Petit et al. 1997); downregulation of VEGF, interleukin (IL)-8, and basic fibroblast growth factor (bFGF) expression in tumor xenografts; and involution of tumor blood vessels, with inhibition of tumor growth (Perrotte et al. 1999). In addition, cetuximab treatment significantly inhibits tumor growth and metastasis in mice bearing either 253J B-V tumors (Perrotte et al. 1999) or human prostate tumors (Karashima et al. 2002), and modestly inhibits spontaneous metastasis in a severe combined immunodeficiency mouse xenograft model of metastatic melanoma, an effect that may reflect antibody-dependent cellular cytotoxicity (Naramura et al. 1993, Mendelsohn 2001).

\section{$A B X-E G F$}

Other anti-EGFR mAbs in clinical development include the fully humanized ABX-EGF (Abgenix) selected from a panel of human IgG2 anti-EGFR mAbs generated by immunizing the XenoMouse $\operatorname{IgG} 2$ strain with cells of the human cervical epidermal cancer cell line A431, which express more than $10^{6}$ EGFR molecules per cell (Davis et al. 1999, Yang et al. 1999, 2001). In vitro, AGX-EGF blocks the binding of both EGF and TGF- $\alpha$ to the receptor, inhibits EGF-activated EGFR tyrosine phosphorylation and inhibits tumor cell activation and proliferation (Yang et al. 2001, Lynch \& Yang 2002). Like cetuximab, ABX-EGF causes EGFR internalization in tumor cells and blocks activation of the EGFR tyrosine kinase.

In vivo experiments with human tumor xenografts in nude mice show that antitumor activity mediated by ABX-EGF correlates with the levels of EGFR expression on the human tumors tested. ABX-EGF blocks formation of human epidermoid carcinoma A431 xenografts in athymic mice, mediates therapeutic elimination of established tumors, and acts cooperatively with chemotherapeutic agents to cause tumor regression (Lynch \& Yang 2002). Recently, in vitro and in vivo efficacy has been shown in studies of prostate cancer (Wang et al. 2003) and renal cell carcinoma (Wang et al. 2003) that were performed to support clinical trials for these indications. In the prostate tumor study, there was evidence of an antiangiogenic effect (Wang et al. 2003).

\section{Other antibodies}

The humanized antibodies MDX-447 (Medarex), with dual activity against EGFR and the Fc receptor, and EMD 72000 (EMD Pharmaceuticals) are additional promising agents currently being evaluated in clinical trials for several tumors including head and neck cancer and ovarian cancer respectively. Unique antibodies raised against mutant forms of the EGFR (i.e. EGFRvIII) are also under development (Mishima et al. 2001) with growth suppression of intracranial xenografted glioblastomas overexpressing mutant EGFRs by systemic administration of $\mathrm{mAb} 806$, a novel $\mathrm{mAb}$ directed to the receptor (Mishima et al. 2001). In this review, discussion is focused on the EGFR-specific mAbs cetuximab and ABX-EGF since they are the most advanced of their class.

\section{TKIs}

The TKIs are synthetic, mainly quinazoline-derived, low molecular weight molecules that interact with the intracellular tyrosine kinase domain of several receptors, including EGFR, and inhibit ligand-induced receptor phosphorylation by competing for the intracellular $\mathrm{Mg}_{-}$ ATP-binding site (Ciardiello 2000). Over the past 20 years, several hundred TKIs have been developed (Ciardiello 2000). TKIs that target the EGFR and are sufficiently advanced in clinical development are shown in Table 3 .

\section{Gefitinib}

Gefitinib (Iressa; AstraZeneca), formerly known as ZD1839, has received approval in 18 countries (to date) including the United States, Canada, Japan, Australia, and other countries in the Far East and the Americas, as a single agent for the treatment of refractive NSCLC. Gefitinib is an orally active, low molecular weight, synthetic anilinoquinazoline that inhibits several receptor tyrosine kinases, particularly EGFR (Ciardiello et al. 2000, Arteaga \& Johnson 2001, AstraZeneca Pharmaceuticals LP 2003). Gefitinib inhibits the kinase activity of isolated EGFR with an $\mathrm{IC}_{50}$ in the nanomolar range (Woodburn et al. 2000). However, higher concentrations may be required to block EGFR activity in vivo, due to the high intracellular concentration of ATP (Arteaga \& Johnson 2001). At concentrations more than 100-fold greater than those required to inhibit EGFR, gefitinib inhibits other tyrosine kinase receptors, including HER2 (Woodburn et al. 2000, Arteaga \& Johnson 2001, Moulder et al. 2001). This additional receptor activity 
Harari: EGFR inhibition strategies in oncology

Table 3 TKIs in clinical trials

\begin{tabular}{llll}
\hline Agent & Type & Generic/trade name & Institution \\
\hline ZD1839 & erbB1 & ${ }^{*}$ Gefitinib/Iressa & AstraZeneca \\
OSI-774 & erbB1 & Erlotinib HC1/Tarceva & OSI/Genentech/Roche \\
Cl-1033 & pan erbB & Canertinib & Pfizer \\
EKB-569 & erbB1/2 & - & Wyeth Ayerst \\
GW2016 & erbB1/2 & - & GlaxoSmithKline \\
PKI-166 & erbB1/2 & - & Novartis \\
\hline
\end{tabular}

*Approved.

may have clinical significance, and clinical studies in this regard are in progress.

Gefitinib demonstrates antiproliferative activity in tumor cell cultures and in human tumor xenografts, both as a single agent and in combination with cytotoxic chemotherapy or radiotherapy. With co-administration, gefitinib shows additive or even synergistic effects (Sirotnak et al. 2000, Sirotnak 2003). The additive or synergistic effects of gefitinib achieved in combination therapy did not necessarily require high levels of EGFR expression in the tumor models tested. These preclinical findings influenced subsequent clinical trial strategies where high level of EGFR expression by the tumor was not a criterion for study entry (see INTACT trials, below).

Preclinical studies indicate that gefitinib affects many of the same intracellular signaling pathways inhibited by anti-EGFR mAb therapy. Gefitinib inhibits the growth of a range of human cancer cells in vitro and in vivo, and there is evidence that the inhibitor acts by inducing cellcycle arrest and/or apoptosis (Ciardiello et al. 2000, Woodburn et al. 2000, Albanell et al. 2001, Magne et al. 2002, Di Gennaro et al. 2003). As with the EGFR-specific mAbs, the TKIs appear to act by several antitumor mechanisms. Gefitinib appears to indirectly inhibit angiogenesis since treatment is associated with growth inhibition of human colon, breast, ovarian, and gastric cancer cells in vitro, accompanied by a reduction in VEGF, bFGF, and TGF- $\alpha$ production and substantially reduced tumor microvessel density (Ciardiello et al. 2000). Gefitinib prevents EGF-induced upregulation of VEGF and IL-8, restricts EGF-induced endothelial cell migration and tube formation in vitro, and inhibits neovascularization in a mouse cornea model (Hirata et al. 2002). In cultured human cutaneous squamous carcinoma cells, gefitinib inhibits molecular pathways involved in cell migration and invasiveness, thereby reducing the ability of cells to invade a complex extracellular matrix (Barnes et al. 2003).

\section{Erlotinib}

Erlotinib hydrochloride (Tarceva), formerly known as CP358,744 and subsequently as OSI-774, is a potent and reversible quinazoline-type inhibitor of human EGFR tyrosine kinase in the nanomolar range. Erlotinib inhibits proliferation of DiFi human colon tumor cells at submicromolar concentrations in cell culture, blocks cell-cycle progression at the G1 phase and triggers apoptosis (Moyer et al. 1997). At doses of $100 \mathrm{mg} / \mathrm{kg}$, erlotinib completely prevents EGF-induced phosphorylation of EGFR in human HN5 tumor xenografts in athymic mice and of hepatic EGFR of the treated mice (Moyer et al. 1997). Substantial growth inhibition of human tumor xenografts in athymic mice is achieved with lower oral doses of the agent with an $\mathrm{ED}_{50}$ of $10 \mathrm{mg} / \mathrm{kg}$ daily for a 20-day treatment period (Pollack et al. 1999). Combination chemotherapy of erlotinib with cisplatin produces a significant response greater than that of cisplatin alone, with no detected effects on body weight or lethal toxicity.

In vitro and in vivo studies have shown that erlotinib has activity against human colorectal, head and neck, NSCLC and pancreatic tumor cells (Akita \& Sliwkowski 2003). Recent preclinical studies suggest that erlotinib may also have activity against tumors that are dependent on HER2 activation for growth and/or survival. In preclinical studies, combining erlotinib with cisplatin, doxorubicin, gemcitabine or low-dose paclitaxel had an additive effect on antitumor activity with no increase in toxicity (Akita \& Sliwkowski 2003). Submicromolar concentrations of erlotinib can specifically inhibit mutant EGFRvIII transformed cells (Iwata et al. 2002). This is noteworthy because EGFRvIII is prevalent in a high percentage of glial tumors (Jungluth et al. 2003).

\section{Other TKIs}

Other TKI agents in clinical development include the irreversible pan-erbB inhibitor canertinib (CI-1033; Pfizer), EKB-569 (Wyeth Ayerst), GW572016 (GlaxoSmithKline), and the pyrrolopyrimidine compound, PKI-166 (Novartis). In contrast to the mAbs, TKIs do not elicit an immune response. They do appear to inhibit internalization of EGF receptors. A recent study demonstrated that the EGFRspecific TKI, PD158780, inhibits the recruitment of EGFR to clathrin-coated pits, the first stage in receptor endocytosis (Sorkina et al. 2002). Unlike the mAbs, TKIs show 
activity against other receptors such as HER2 at high concentrations (gefitinib and erlotinib) or all four HER (erbB) receptors as in the case of canertinib. The clinical significance of the differences in activity between mAbs to EGFR and the TKI compounds is not yet clear. The agents furthest along in clinical development, gefitinib and erlotinib, are used in this review as examples of TKIs with specificity for EGFR.

\section{Clinical activity of EGFR inhibitors}

The mAbs such as cetuximab and ABX-EGF, and TKIs such as gefitinib and erlotinib display markedly different pharmacokinetic (PK) profiles, and these compounds differ in their route and frequency of administration. These characteristics have important implications for patient convenience on the one hand, and for safety characteristics on the other. As proteins, cetuximab and ABX-EGF are subject to degradation in the digestive system and must, therefore, be administered by i.v. injection. In contrast, gefitinib and erlotinib are administered orally, a potential advantage for chronic therapy (Baselga et al. 2002). On the other hand, the TKIs need to be administered daily, and oral dosing is associated with dose-limiting gastrointestinal toxicity (Albanell et al. 2001). The mAbs do not appear to induce significant diarrhea because of their mode of delivery and inability to cross basement membranes into the lumen of the gastrointestinal tract (Herbst \& Hong 2002). However, the large size of these macromolecules may limit their ability to penetrate easily into some anatomical compartments, such as the central nervous system.

Cetuximab, ABX-EGF, gefitinib, and erlotinib have all been evaluated in clinical trials both as single agents and in combination with conventional chemotherapy or radiation therapy. Because EGFR inhibition and conventional anticancer therapy act via different cytotoxic mechanisms, combination therapy offers the potential advantages of additive or synergistic activity without overlapping toxicity profiles (Kim et al. 2001). Numerous preclinical studies have demonstrated additive or synergistic antitumor activity, both in vitro and in vivo.

Treatment with cetuximab, ABX-EGF, gefitinib or erlotinib is commonly associated with the development of an acneiform rash, generally involving the face, neck and upper torso. The rash is typically mild (grade 1-2), does not require dose adjustment, and resolves or stabilizes with continued treatment. This cutaneous effect appears to be a direct biological response to EGFR inhibition (Busam et al. 2001), and there is suggestive evidence that development of an acneiform rash may be predictive of an ultimate response to therapy (Kies et al. 2002, Cohen 2003). Indeed, the presence and intensity of skin rash was found to correlate with increased survival in several clinical trials across multiple malignancies (Saltz et al. 2003).

\section{Cetuximab}

Cetuximab is administered i.v. at doses of $200-400 \mathrm{mg} / \mathrm{m}^{2}$ and has a mean half-life of $114 \mathrm{~h}$ (range $75-188 \mathrm{~h}$ ), thus allowing weekly administration. The kinetics of cetuximab are nonlinear, with complete saturation of systemic clearance, and are unaffected by co-administration with cisplatin (Baselga 2001). In three phase I studies of patients with cancer of the head and neck or NSCLC, a loading dose of $400 \mathrm{mg} / \mathrm{m}^{2}$ of cetuximab and a weekly maintenance dose of $250 \mathrm{mg} / \mathrm{m}^{2}$ was associated with near complete saturation of EGFR within the tumor, an important criterion for optimal activity (Baselga et al. 2000). Adverse effects were minimal and a maximum tolerable dose (MTD) was not reached. Antibodies against cetuximab were detected in only one patient out of a total of 52 subjects treated. The PK profile of cetuximab does not change following repeated doses, confirming a lack of immunogenicity (Mendelsohn 2001). Subsequent clinical trials have been conducted using this dosing regimen.

Several phase I and I/II studies were undertaken to investigate the tolerability of cetuximab in combination with conventional cytotoxic agents such as cisplatin or carboplatin and 5-fluorouracil (5FU) in patients with recurrent or metastatic squamous cell carcinoma of the head and neck (SCCHN) (Vega-Villegas et al. 2003), gemcitabine/carboplatin in chemotherapy-naive patients with advanced stage IV NSCLC (Robert et al. 2003), paclitaxel and carboplatin in previously untreated patients with stage IV NSCLC (Kelly et al. 2003), or cetuximab in combination with chemotherapy or radiotherapy (Robert et al. 2001, Needle 2002). In these studies, the most common toxicity associated with cetuximab was acneiform rash (mainly grade 1-2) and the most common grade 3 toxicity was fatigue. Allergic/hypersensitivity reactions were less common. A series of studies (phases I-III) of cetuximab + cisplatin or carboplatin in SCCHN have shown that toxicities are generally nonoverlapping (Shin et al. 2001, Baselga et al. 2002, Burtness et al. 2002, Kies et al. 2002). Various studies that have been carried out with cetuximab, either as monotherapy or in combination with conventional therapy, are summarized in Table 4.

The US product labeling for cetuximab (Erbitux) in the treatment of irinotecan-refractory colorectal cancer describes the risk of severe infusion reactions $(3 \%$ of patients), $90 \%$ of these being associated with the first infusion. It is rarely fatal $(<1$ in 1000). As with gefitinib (Iressa, see below) and conventional cancer therapy, there is a potential risk of developing interstitial lung disease 


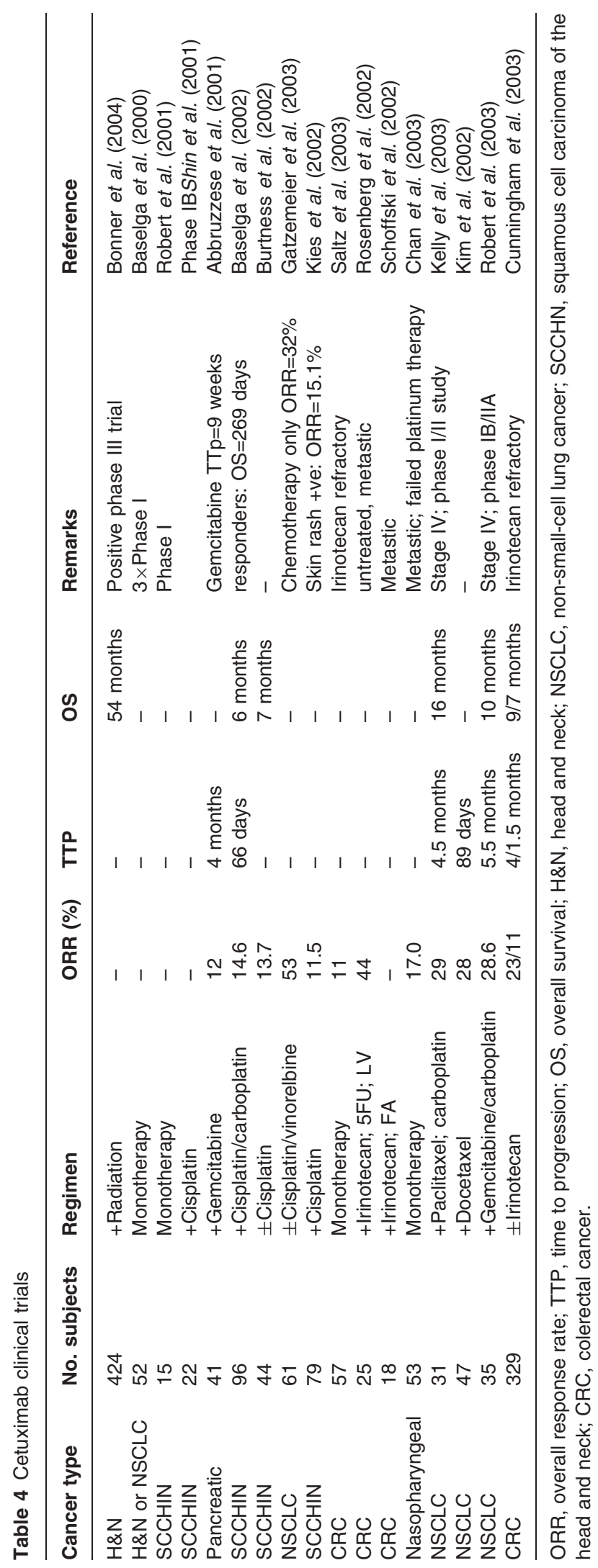


(ILD). ILD was reported for 3 of 633 patients $(<0.5 \%)$ with advanced colorectal cancer who were administered cetuximab. As per the FDA News statement, it was difficult to determine whether Erbitux treatment caused the ILD. Other serious adverse reactions include fever $(55 \%)$, sepsis $(3 \%)$, kidney failure $(2 \%)$, pulmonary embolus $(1 \%)$, dehydration $(5 \%$ cetuximab + irinotecan; $2 \%$ cetuximab only), and diarrhea ( $6 \%$ cetuximab + irinotecan, $0 \%$ cetuximab only).

With respect to efficacy, a single arm, multicenter, open-label phase II trial of cetuximab+irinotecan in colorectal cancer patients $(n=121)$ refractory to irinotecan alone demonstrated partial response in $23 \%$ of patients and minor response or stable disease in $31 \%$ of patients (Saltz et al. 2001). Subsequently, results for a total of 138 patients were reported where the overall response rate was $15 \%$ and the median duration of the response was 6.5 months. A larger European phase II trial (the BOND study) was conducted comparing a combination of cetuximab and irinotecan (Arm A; 218 patients) with cetuximab single-agent treatment (Arm B; 111 patients) in EGFR-positive, irinotecan-refractory, metastatic colorectal cancer (Cunningham et al. 2003). Outcome analysis showed response rates of $22.9 \%$ (cetuximab + irinotecan) and $10.8 \%$ (cetuximab monotherapy). Median survival time was longer with combination therapy (8.6 months) than with cetuximab alone (6.9 months), but the difference was not statistically significant. However, the significance level might have been impacted by the study protocol, which permitted crossover to the alternative therapy. Oxaliplatin treatment had also previously failed in $63 \%$ of patients in this study.

Encouraging results, with expected toxicities, were seen in two other European phase II trials. These included the open-label, Lung Cancer CetuximAb Study (LUCAS), in patients with advanced, EGFR-positive NSCLC, comparing cetuximab in combination with cisplatin or vinorelbine with cisplatin or vinorelbine treatment alone (Gatzemeier et al. 2003), and a study with cetuximab used in combination with a FOLFIRI (irinotecan/5FU/folinic acid (FA)) regimen in patients with metastatic colorectal cancer (Van Laethem et al. 2003). In the United States, a phase III trial (the EPIC study) of cetuximab + I rinotecan vs irinotecan, as second-line treatment in patients with metastatic EGFR-positive colorectal cancer, has been initiated. Another US phase III trial (the EXPLORE study), that is recruiting patients with metastatic EGFRpositive colorectal cancer, will evaluate cetuximab administered in combination with 5FU/leucovorin (LV) and oxaliplatin (FOLFOX) vs FOLFOX only.

In June 2004, results of an international, randomized phase III clinical trial of 424 patients who received radiation \pm cetuximab for advanced head and neck cancer demonstrated a near doubling of median survival for patients treated with radiation + cetuximab, 54 months vs 28 months for patients treated with radiation alone. There was a statistically significant improvement $(P=0.02)$ in locoregional disease control ( $8 \%$ at 2 years) and overall survival (13\% at 3 years) favoring the cetuximab arm (Bonner et al. 2004). In addition to providing new potential treatment options for advanced head and neck cancer patients, this pivotal trial demonstrates survival benefit using a molecularly targeted agent used as a radiation sensitizer. This finding will likely stimulate many new clinical trials for other cancer types in which radiation plays a central treatment role.

\section{ABX-EGF}

PK and pharmacodynamic studies were conducted with i.v. ABX-EGF to determine optimal dosing in cancer patients. Saturation of EGFR was assessed by clearance and the incidence and severity of the characteristic acneiform rash. In a phase I trial, 43 patients with renal, prostate, NSCLC, pancreatic, gastroesophageal or colorectal cancer received ABX-EGF weekly for up to 4 weeks at doses up to $2.5 \mathrm{mg}$ / $\mathrm{kg}$ (Roskos et al. 2002). All patients who received doses of 2 or $2.5 \mathrm{mg} / \mathrm{kg}$ ABX-EGF developed rashes that resolved within 4 weeks of the last dose. No human anti-human antibodies (HAHAs) were detected in any patient and no alterations in PK occurred in any subject, consistent with the absence of HAHA development. It was concluded that the low PK variability, absence of immunogenicity, and high potency of ABX-EGF permitted dosing up to 2.0$2.5 \mathrm{mg} / \mathrm{kg}$, producing evidence of EGFR blockade (acneiform rash) while maintaining a tolerable safety profile. In another phase I trial, excluding skin rash, the most common grade 2 or higher adverse events reported were asthenia and back pain (each 15\%), followed by unspecified pain $(13 \%)$. Diarrhea was minimal (7\%; grade $1-2)$ and not dose-related. There was no anaphylaxis and no allergic or infusion-related reactions were observed (Figlin et al. 2002).

A two-part, phase II monotherapy trial of eight weekly i.v. infusions of ABX-EGF was conducted in patients with renal cell carcinoma in whom IL-2/ interferon- $\alpha$ treatment failed or who were not able to receive this treatment (Schwartz et al. 2002). Stable or responding patients were eligible for extended weekly treatment, at the assigned dose $(1.0,1.5$ or $2.0 \mathrm{mg} / \mathrm{kg})$, for 8 additional months or until disease progression. At the time of report, 58 patients had been treated and 32 had completed one 8-week cycle. Two objective responses were seen at doses of 1.0 and $1.5 \mathrm{mg} / \mathrm{kg}$. Minor response or stable disease was observed in $58 \%$ of patients, while $36 \%$ had progressive disease. Grade $2 / 3$ adverse events were skin rash, pruritus, dyspnea, fatigue, diarrhea, 
abdominal pain, nausea and vomiting. Acneiform rash (grades 1 and 2) was the most frequently observed adverse event $(61 \%)$. In the same series of patients, when the dosage was increased to $2.5 \mathrm{mg} / \mathrm{kg}$ (21 patients) the incidence of skin rash increased to $100 \%$ (Schwartz et al. 2002). No HAHAs were detected.

A multicenter trial of ABX-EGF monotherapy was conducted in patients with metastatic colorectal cancer (Meropol et al. 2003). At the time of report, 44 patients had received treatment $(2.5 \mathrm{mg} / \mathrm{kg}$, i.v. for $1 \mathrm{~h}$, weekly for 3 weeks). Maximum rash intensity was generally achieved by week 3 of treatment. There were no complete responses, $9 \%$ of subjects showed a partial response, there was stable disease in $52 \%$, and progressive disease in $39 \%$ of patients. There were no cases of anaphylaxis, other allergic reactions, or medically significant transfusion reactions, and no incidence of HAHA response.

Abgenix, in collaboration with Amgen Inc., are conducting phase II trials of ABX-EGF monotherapy in hormone-resistant prostate cancer patients, single-arm combination therapy (first-line treatment) in colorectal cancer, and two-arm combination ABX-EGF + chemotherapy vs chemotherapy alone (first-line treatment) in NSCLC.

\section{Gefitinib}

Following a single oral dose of up to $700 \mathrm{mg}$ gefitinib in both healthy volunteers and patients with advanced malignancies, peak plasma drug concentration was attained at $3-7 \mathrm{~h}$, with an elimination half-life of approximately $48 \mathrm{~h}$ (Baselga \& Averbuch 2000). Daily oral administration to cancer patients results in a 2 -fold accumulation of drug compared with a single-dose administration and steady-state plasma concentrations are achieved within 10 days. Long-term administration of gefitinib was generally well tolerated at doses up to 600 $\mathrm{mg}$ /day. Higher doses were associated with dose-limiting toxicities, such as grade 3 diarrhea (Ranson et al. 2002). The gastrointestinal toxicity of gefitinib appears to reflect the direct exposure of intestinal epithelial cells to EGFR inhibition via oral administration.

As with cetuximab, gefitinib labeling carries a warning concerning pulmonary toxicity (ILD). The overall incidence is about $1 \%$, with approximately one-third of cases being fatal (AstraZeneca Pharmaceuticals LP 2003). This warning was included as a result of post-approval experience in Japan where a small proportion of patients (170 out of $10000(1.7 \%)$ ) receiving the drug developed fatal ILD (Schultz 2003). Although worthy of careful evaluation, it should be noted that ILD is also seen in patients with advanced lung cancer treated by conventional chemotherapy or radiotherapy. Other precautions concern the potential for hepatic toxicity due to asympto- matic increases in liver transaminases in patients treated with gefitinib. Drug-related adverse events (with an incidence of $\geq 5 \%$ in either the 250 or $500 \mathrm{mg}$ /day dose group) listed in the Iressa product labeling are, in decreasing order of frequency, diarrhea, rash, acne, dry skin, nausea, vomiting, pruritus, anorexia, asthenia and weight loss. These effects are mainly dose-dependent.

As summarized in Table 5, a number of single-agent clinical trials have been conducted with gefitinib in a range of solid malignancies, including SCCHN at doses of $250 \mathrm{mg}$ gefitinib per day (Cohen et al. 2003b) and $500 \mathrm{mg}$ / day (Cohen et al. 2002, 2003a), in renal cell carcinoma (Drucker et al. 2002, Dawson et al. 2003), and advanced breast cancer (Baselga et al. 2003, Fountzilas et al. 2003, Robertson et al. 2003). In one of the SCCHN studies, the development of skin toxicity was found to be a statistically significant predictor of response and improved outcome (Cohen et al. 2003a), which is consistent with the experience with cetuximab (Saltz et al. 2003).

The Iressa Dose Evaluation in Advanced Lung Cancer (IDEAL) phase II trials, IDEAL-1 and IDEAL-2, each evaluated single-agent gefitinib therapy at daily doses of 250 and $500 \mathrm{mg}$ in patients with NSCLC (Douillard et al. 2002, Kris et al. 2002, 2003, Cella 2003, Fukuoka et al. 2003, Herbst 2003a). Efficacy outcomes were similar for both dosage groups, with overall response rates of 18.4 $19 \%$ reported in IDEAL- 1 and $8.8-11.8 \%$ in IDEAL-2. Across both trials, $35-43 \%$ of patients experienced symptom improvement and 22-34\% reported improved quality of life (QOL) (Douillard et al. 2002, Cella 2003, Fukuoka et al. 2003, Herbst 2003a). As expected from earlier clinical trial results, the $250 \mathrm{mg}$ dose administered in IDEAL-2 was well tolerated, with generally mild (grade $1-$ 2) toxicities, including rash $(43.1 \%)$, acne $(24.5 \%)$, and diarrhea $(48 \%)$. Based on these studies, particularly the IDEAL-2 trial, gefitinib gained subsequent approval in several countries, including the United States, for singleagent use in NSCLC patients who fail to respond to at least two prior chemotherapy regimens.

The Iressa NSCLC Trial Assessing Combination Treatment (INTACT) phase III trials, INTACT-1 $(n=1093)$ and INTACT-2 $(n=1037)$, evaluated the safety and efficacy of adding either gefitinib or placebo to standard chemotherapy regimens (gemcitabine + cisplatin or paclitaxel + carboplatin) for the treatment of chemotherapy-naive patients with advanced NSCLC (Giaccone et al. 2002, Johnson et al. 2002). In both trials, the toxicities experienced by patients receiving gefitinib were comparable to those associated with chemotherapy alone. As expected, dose-dependent acneiform rash and diarrhea were also reported. Overall, the toxicity profile associated with the addition of gefitinib to these regimens 


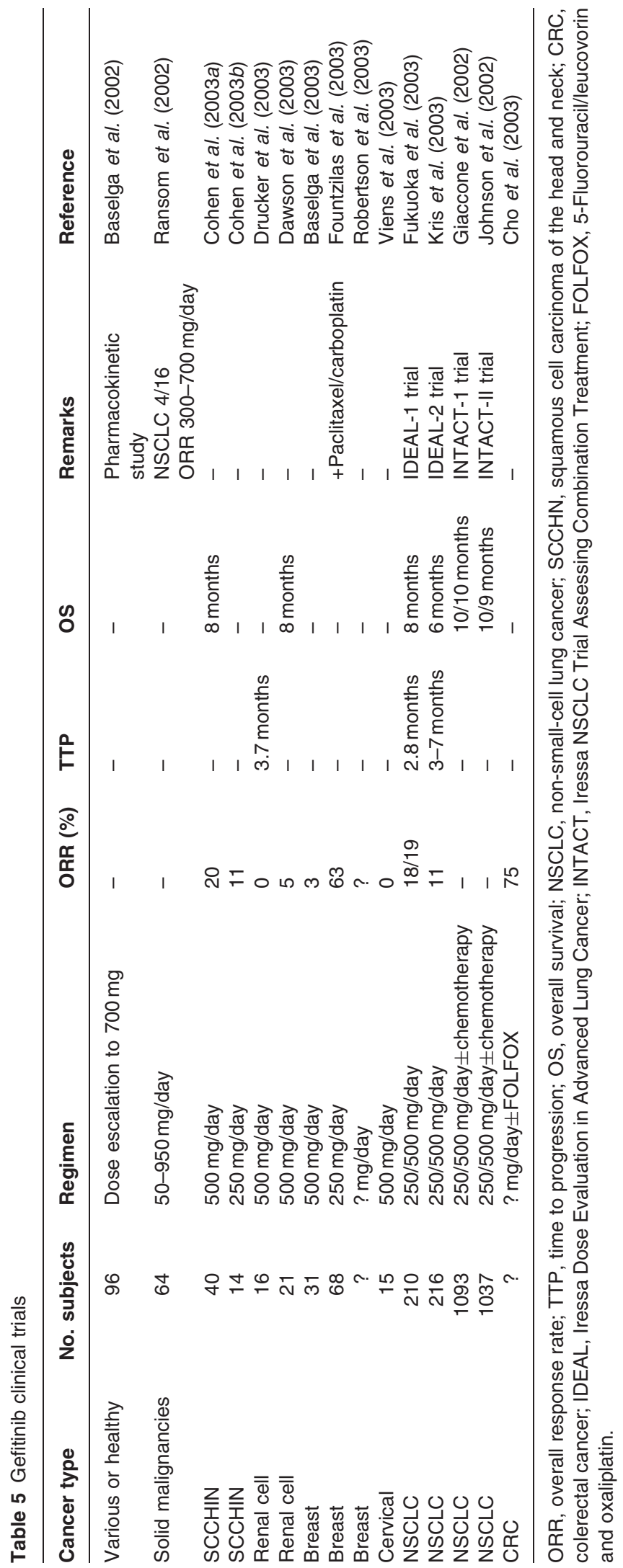


was considered acceptable. However, no improvement was observed relative to placebo in overall survival, progression-free survival, time to worsening of symptoms, objective tumor response, QOL, or safety (Giaccone et al. 2002, Johnson et al. 2002, Saul 2003). The INTACT trials were well designed and the results were considered definitive (Saul 2003).

The reason for the failure of gefitinib to show clinical advantage in combination with chemotherapy in lung cancer remains unclear. Multivariate analysis of prognostic factors for overall survival in INTACT-1 and INTACT-2 trial data did not show any consistent effect of gefitinib combined with chemotherapy, compared with chemotherapy alone, on any known prognostic factors for survival outcome in advanced NSCLC (Giaccone et al. 2003). Furthermore, post hoc subset analysis did not reveal any susceptible subpopulations (Herbst et al. 2003). Some authors have argued that these phase III studies had a 'fatal flaw' in their design by not requiring study subjects to show positive EGFR status (Dancey \& Freidlin 2003). However, a definitive correlation between EGFR status (Dawson et al. 2003), or that of other biological markers (Baselga et al. 2003), and response to gefitinib treatment (or other EGFR inhibitors) has yet to be demonstrated. This relationship is being more systematically investigated using 732 tumor samples collected during the two INTACT trials (Giaccone et al. 2003).

\section{Erlotinib}

The pharmacokinetics of erlotinib are dose-dependent, and repetitive daily treatment does not result in drug accumulation when administered at an average dosage of $150 \mathrm{mg} /$ day. The elimination half-life averages approximately $24 \mathrm{~h}$ (Hidalgo et al. 2001). Plasma concentrations exceeded those that were associated with activity in preclinical models. The principal dose-limiting toxicities in phase I trials of erlotinib were acneiform rash and diarrhea (Grunwald \& Hildago 2003b). In a phase I study of erlotinib in patients with advanced solid malignancies, no severe toxicities prevented dose escalation from 25 up to $100 \mathrm{mg}$ /day. However, the incidence of severe diarrhea and/or cutaneous toxicity was unacceptably high at erlotinib doses exceeding $150 \mathrm{mg}$, administered once daily for 3 weeks, every 4 weeks (Hidalgo et al. 2001). The diarrhea was considered dose limiting at $200 \mathrm{mg}$ /day but was less frequent at $150 \mathrm{mg} /$ day and manageable at this dose with loperamide. Based on these provisional data, $150 \mathrm{mg} /$ day was selected as the MTD for the phase II program (Herbst 2003b).

Erlotinib has been evaluated alone vs in combination therapy with temozolomide in a phase I study of patients with malignant glioma (Prados et al. 2003). Concomitant use of enzyme-inducing epileptic drugs reduced exposure of the patient to erlotinib and its active metabolite. The objective responses were encouraging, and a corresponding phase II study was initiated. A phase IB trial of escalating doses of erlotinib in combination with a standard dose gemcitabine regimen was conducted in patients with advanced pancreatic adenocarcinoma and other malignancies potentially responsive to gemcitabine (Dragovich et al. 2003). Preliminary results indicated some activity and no serious toxicities at dosages of 100 or $250 \mathrm{mg} /$ day of erlotinib, although one patient with lung cancer developed fatal pulmonary toxicity, which was attributed to gemcitabine treatment and prior radiotherapy. This combination is being compared with standard gemcitabine therapy in a phase III randomized trial initiated by the National Cancer Institute of Canada, as described below.

Preliminary results from a phase II trial of erlotinib in patients with bronchioloalveolar cell carcinoma (BAC) were recently reported (Miller et al. 2003). A total of 33 patients with proven BAC or a variant had been treated at the time of the report. The authors concluded that erlotinib is an active agent in this disease and, if this is confirmed with additional patient accrual, a follow-up phase III trial is planned. A possible difference in responsiveness to the drug between smokers and nonsmokers is being investigated.

Two phase III trials of erlotinib (150 mg/day)+chemotherapy were conducted in patients with first-line metastatic NSCLC. These trials, which have similar protocols, are called TRIBUTE (Herbst et al. 2004) in the United States, and TALENT outside of the United States (Gatzemeier et al. 2004). As with the INTACT trials with gefitinib in NSCLC, neither of these erlotinib trials met the primary endpoint of improving overall survival. In the TRIBUTE study, one of the secondary endpoints, time to symptomatic progression, did achieve statistical significance but this did not translate into improvement in overall survival or time to disease progression. The addition of erlotinib to chemotherapy was generally well tolerated and there were no unexpected toxicities. The results, while disappointing, were not entirely unexpected in view of the failure of the gefitinib trials in the same clinical setting.

A 700-patient, randomized, phase III trial of erlotinib monotherapy (150 mg/day) vs placebo in second- or thirdline metastatic NSCLC completed enrollment in January 2003. This study was conducted by OSI Pharmaceuticals in collaboration with the National Cancer Institute of Canada Clinical Trials Group (NCIC CTG). Although the addition of erlotinib to doublet chemotherapy regimens in advanced lung cancer failed to identify a survival advantage over chemotherapy alone, this new study met the primary endpoint of improving overall survival from 4.7 to 6.7 months, as well as secondary endpoints of 


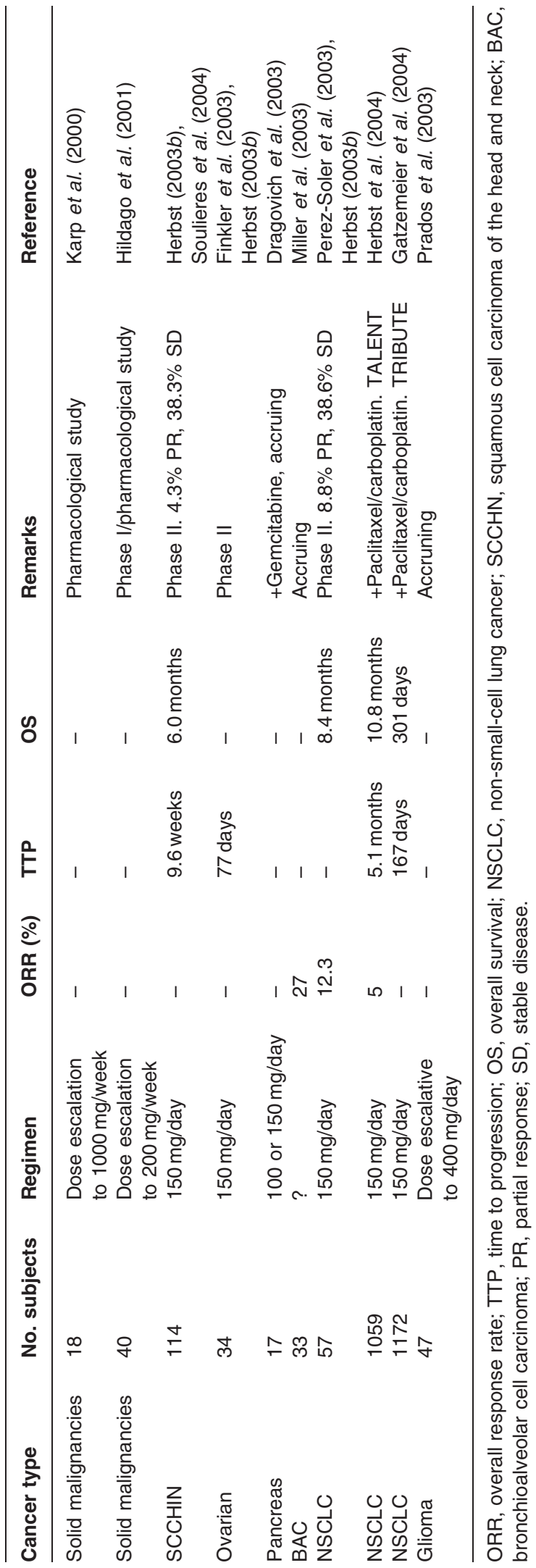




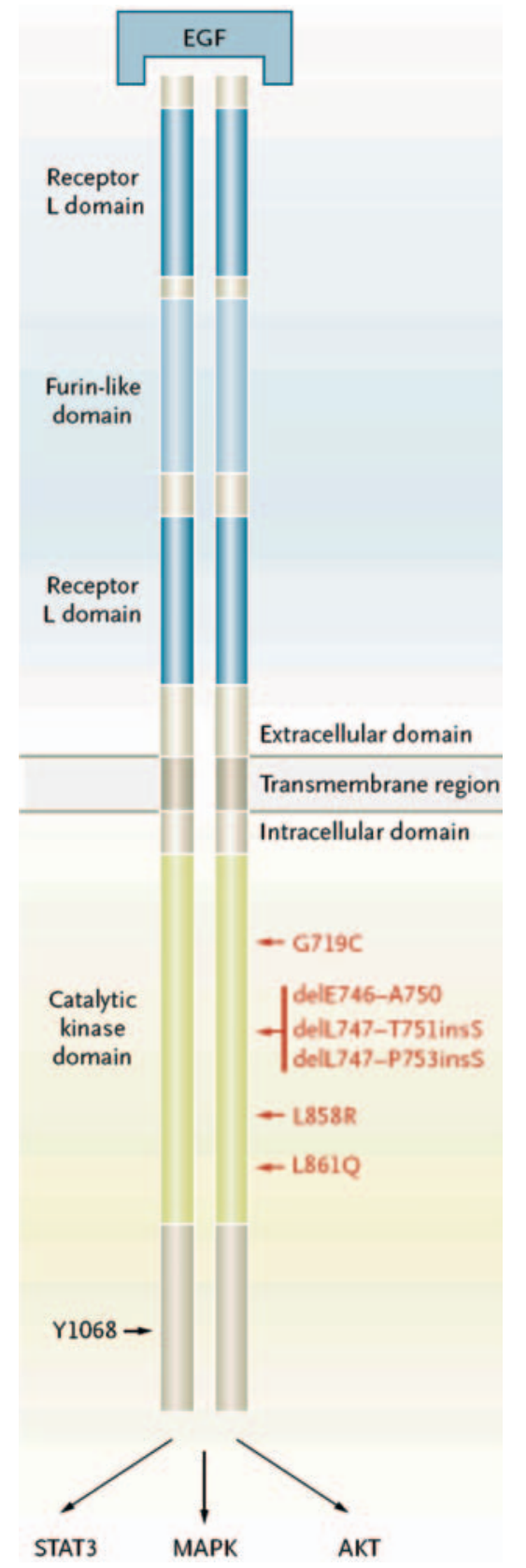

Figure 3 Mutations identified in the EGFR tyrosine kinase domain (red) conferring sensitivity to gefitinib in non-small cell lung cancer patients. Adapted with permission from Lynch et al. (2004).

improving time to symptomatic progression, progressionfree survival and response rate (Shepherd et al. 2004). Additionally, OSI Pharmaceuticals and Genentech have initiated a randomized, placebo-controlled, phase III trial evaluating erlotinib in combination with gemcitabine in 450 patients with previously untreated metastatic pancreatic cancer; again in collaboration with the NCIC CTG.

\section{Discussion}

Molecular inhibitors of EGFR signaling represent a highly promising class of molecular targeted anticancer agents. A series of EGFR inhibitors from both the mAb and TKI class have demonstrated clear clinical activity as monotherapy in the treatment of refractory solid malignancies. Gefitinib has received approval for refractory NSCLC in several countries, including the United States (FDA approval May 2003). Cetuximab has also received recent FDA approval in the United States (February 2004) and Switzerland for colorectal cancer that is unresponsive to irinotecan. Preliminary reports regarding the capacity of erlotinib to extend overall survival in advanced, recurrent NSCLC patients suggest that this small molecule EGFR inhibitor may also gain FDA approval in the future months. If so, this would represent the third molecular inhibitor of EGFR signaling to gain FDA approval in cancer therapy over the last 12-18 months, validating a central role of EGFR as an important molecular target in human epithelial tumors.

Despite the recent success of EGFR inhibitory agents in gaining FDA approval, there remain several major gaps in our knowledge regarding the function, activity and preferred clinical applications for EGFR inhibitors. The preclinical data regarding EGFR inhibitors have been exceptionally strong, but not fully predictive of clinical trial results. Indeed, preclinical studies predicted a highly favorable interaction of EGFR inhibition combined with cytotoxic chemotherapy in NSCLC that was not substantiated in major lung cancer trials such as the INTACT and TALENT/TRIBUTE trials with gefitinib and erlotinib respectively. It remains to be clarified whether these results reflect a generic adverse interaction between EGFR inhibitors and concurrent cytotoxic chemotherapy in lung cancer, or whether this reflects inadequate patient selection in the absence of defined parameters that can better predict those patients likely to respond favorably to EGFR inhibitors. With regard to patient selection, brand new reports suggest that a subgroup of patients with lung cancer carry specific mutations (Fig. 3) in the EGFR gene which correlate with the likelihood of response to the EGFR inhibitor gefitinib (Lynch et al. 2004, Paez et al. 2004). This type of finding offers future potential to more accurately screen and predict responders for specific EGFR inhibitors.

The rational selection of cancer patients for EGFR inhibitor therapies remains a major challenge. Unlike the use of Herceptin in breast cancer therapy, where the link between overexpression of the molecular target (erbB-2) and response to therapy is relatively clear, the association between EGFR overexpression and response to EGFR inhibitor therapy does not appear straight forward. The complexity of the erbB signaling network and the 
significance of various activated downstream markers remains under intense investigation with regard to potential prognostic and predictive value. Examination of molecular footprints from tumor specimens of patients on anti-EGFR inhibitor trials, and initiation of abbreviated 'test response trials', which preview the activity of an EGFR inhibitor in individual patients (based on biomarker or imaging response), hold promise to further advance this investigational field.

The impact of EGFR inhibitors in cancer therapy will ultimately reflect the overall importance of the EGFR as a molecular target in human malignancy. For those patients (individual tumors) in which EGFR signaling represents a dominant driving force for tumor progression, EGFR inhibitor strategies will likely prove of considerable value. However, for those patients (tumors) in which EGFR signaling represents just one of several aberrant molecular growth pathways conferring growth advantage, it would seem unlikely that EGFR inhibition strategies alone will provide substantial therapeutic benefit. In this regard, preclinical studies and innovative clinical trial designs are beginning to examine the capacity of multiple molecular targeted agents to work in concert to achieve tumor regression. Studies to more thoroughly examine optimal sequencing strategies between EGFR inhibitors and cytotoxic therapies such as radiation and chemotherapy are developing. As our understanding regarding mechanisms of actions for EGFR molecular inhibitors increases, more rational clinical designs which examine EGFR inhibitors combined with radiation and chemotherapy will emerge. In parallel, our ability to select patients (tumors) whose molecular profile renders them likely to respond to specific EGFR inhibitory strategies will mature.

\section{Acknowledgement}

Dr Harari holds research agreements with AstraZeneca, ImClone and Genentech.

\section{References}

Aaronson SA 1991 Growth factors and cancer. Science 254 1146-1153.

Abbruzzese JL, Rosenberg A, Xiong Q, LoBuglio A, Schmidt W, Wolff R, Needle M \& Waksal H 2001 Phase II study of antiepidermal growth factor receptor (EGFR) antibody cetuximab (IMC-C225) in combination with gemcitabine in patients with advanced pancreatic cancer. Proceedings of the American Society of Clinical Oncology 20 130a. Abstract 518.

Akita RW \& Sliwkowski MX 2003 Preclinical studies with Erlotinib (Tarceva). Seminars in Oncology 30 15-24.

Albanell J, Rojo F \& Baselga J 2001 Pharmacodynamic studies with the epidermal growth factor receptor tyrosine kinase inhibitor ZD1839. Seminars in Oncology 28 56-66.
Alroy I \& Yarden Y 1997 The ErbB signaling network in embryogenesis and oncogenesis: signal diversification through combinatorial ligand-receptor interactions. FEBS Letters 410 83-86.

Arteaga CL 2002 Epidermal growth factor receptor dependence in human tumors: more than just expression? Oncologist 7 (Suppl 4) 31-39.

Arteaga CL \& Baselga J 2003 Clinical trial design and end points for epidermal growth factor receptor-targeted therapies: implications for drug development and practice. Clinical Cancer Research 9 1579-1589.

Arteaga CL \& Johnson DH 2001 Tyrosine kinase inhibitorsZD1839 (Iressa). Current Opinion in Oncology 13 491-498.

AstraZeneca Pharmaceuticals LP 2003 Iressa (gefitinib) product label.

Barnes CJ, Bagheri-Yarmand R, Mandal M, Yang Z, Clayman GL, Hong WK \& Kumar R 2003 Suppression of epidermal growth factor receptor, mitogen-activated protein kinase, and Pak1 pathways and invasiveness of human cutaneous squamous cancer cells by the tyrosine kinase inhibitor ZD1839 (Iressa). Molecular Cancer Therapeutics 2 345-351.

Baselga J 2001 The EGFR as a target for anticancer therapy focus on cetuximab. European Journal of Cancer 37 (Suppl 4) S16-S22.

Baselga J \& Averbuch SD 2000 ZD1839 ('Iressa') as an anticancer agent. Drugs 60 (Suppl 1) 33-40.

Baselga J, Pfister D, Cooper MR, Cohen R, Burtness B, Bos M, D'Andrea G, Seidman A, Norton L, Gunnett K, Falcey J, Anderson V, Waksal H \& Mendelsohn J 2000 Phase I studies of anti-epidermal growth factor receptor chimeric antibody C225 alone and in combination with cisplatin. Journal of Clinical Oncology 18 904-914.

Baselga J, Trigo JM, Bourhis J, Tortochaux J, Cortes-Funes H, Hitt R, Gascon P, Muesser M, Harstrick A \& Eckardt A 2002 Cetuximab (C225) plus cisplatin/carboplatin is active in patients (pts) with recurrent/metastatic squamous cell carcinoma of the head and neck (SCCHN) progressing on a same dose and schedule platinum-based regimen. Proceedings of the American Society of Clinical Oncology $21226 \mathrm{a}$. Abstract 900.

Baselga J, Albanell J, Ruiz A, Lluch A, Gascon P, Gonzalez S, Guillen V, Sauleda S, Averbuch S \& Rojo F 2003 Phase II and tumor pharmacodynamic study of gefitinib (ZD1839) in patients with advanced breast cancer. Proceedings of the American Society of Clinical Oncology 227 Abstract 24.

Bishop PC, Myers T, Robey R, Fry DW, Liu ET, Blagosklonny MV \& Bates SE 2002 Differential sensitivity of cancer cells to inhibitors of the epidermal growth factor receptor family. Oncogene 21 119-127.

Bonner JA, Giralt J, Harari PM, Cohen R, Jones C, Sur RK, Rabin D, Azarnia N, Needle MN \& Ang KK 2004 Cetuximab prolongs survival in patients with locoregionally advanced squamous cell carcinoma of head and neck: a phase III study of high dose radiation therapy with or without cetuximab. Proceedings of the American Society of Clinical Oncology 23 Abstract 5507.

Burtness BA, Li Y, Flood W, Mattar BI \& Forastiere AA 2002 Phase III trial comparing cisplatin $(\mathrm{C})+$ placebo $(\mathrm{P})$ to $\mathrm{C}+$ anti-epidermal growth factor antibody (EGF-R) C225 in 
patients (PTS) with metastatic/recurrent head and neck cancer (HNC). Proceedings of the American Society of Clinical Oncology 21901 Abstract.

Busam KJ, Capodieci P, Motzer R, Kiehn T, Phelan D \& Halpern AC 2001 Cutaneous side-effects in cancer patients treated with the antiepidermal growth factor receptor antibody C225. British Journal of Dermatology 144 1169-1176.

Carpenter G 2000 The EGF receptor: a nexus for trafficking and signaling. Bioessays 22 697-707.

Carpenter G \& Cohen S 1990 Epidermal growth factor. Journal of Biological Chemistry 265 7709-7712.

Cella D 2003 Impact of ZD1839 on non-small cell lung cancerrelated symptoms as measured by the functional assessment of cancer therapy-lung scale. Seminars in Oncology 30 39-48.

Chan ATC, Hsu MM, Goh BC, Hui EP, Liu TW, Millward M, Chang AY, Ma BB, Hong RL, Lin X et al. 2003 A phase II study of cetuximab (C225) in combination with carboplatin in patients with recurrent or metastatic nasopharyngeal carcinoma who failed on platinum-based chemotherapy. Proceedings of the American Society of Clinical Oncology 22 497 Abstract 2000.

Cho CD, Fisher GA, Halsey J, Jambalos CN, Advani RH, Wakelee H, Lum BL \& Sikic BI 2003 A phase II study of gefitinib in combination with FOLFOX-4 (IFOX) in patients with unresectable or metastatic colorectal cancer. Proceedings of the American Society of Clinical Oncology 22265 Abstract 1062.

Ciardiello F 2000 Epidermal growth factor receptor tyrosine kinase inhibitors as anticancer agents. Drugs 60 (Suppl 1) 25-32.

Ciardiello F, Caputo R, Bianco R, Damiano V, Pomatico G, De Placido S, Bianco AR \& Tortora G 2000 Antitumor effect and potentiation of cytotoxic drugs activity in human cancer cells by ZD-1839 (Iressa), an epidermal growth factor receptor-selective tyrosine kinase inhibitor. Clinical Cancer Research 6 2053-2063.

Cohen EE, Rosen F, Dekker A, Bajda C, Stenson K, Shulman KL, Lamont E, Kozloff M \& Vokes EE 2002 Phase II study of ZD1839 (Iressa) in recurrent of metastatic squamous cell carcinoma of the head and neck (SCCHN). Proceedings of the American Society of Clinical Oncology 21 225a Abstract 899.

Cohen EE, Rosen F, Stadler WM, Recant W, Stenson K, Huo D \& Vokes EE 2003a Phase II trial of ZD1839 in recurrent or metastatic squamous cell carcinoma of the head and neck. Journal of Clinical Oncology 21 1980-1987.

Cohen EE, Stenson K, Gustin DM, Lamont E, Mauer AM, Blair E, Stadler WM, Dekker A, Mallon W \& Vokes EE 2003b A phase II study of $250 \mathrm{mg}$ gefitinib (ZD1839) monotherapy in recurrent or metastatic squamous cell carcinoma of the head and neck (SCCHN). Proceedings of the American Society of Clinical Oncology 22502 Abstract 2021.

Cohen RB 2003 Epidermal growth factor receptor as a therapeutic target in colorectal cancer. Clinical Colorectal Cancer 2 246-251.

Cunningham D, Humblet Y, Siena S, Khayat D, Bleiberg H, Santoro A, Bets D, Mueser M, Harstrick A \& Van Cutsem E 2003 Cetuximab (C225) alone or in combination with irinotecan (CPT-11) in patients with epidermal growth factor receptor (EGFR)-positive, irinotecan-refractory metastatic colorectal cancer. Proceedings of the American Society of Clinical Oncology 22252 Abstract 1012.

Dancey JE \& Freidlin B 2003 Targeting epidermal growth factor receptor - are we missing the mark? Lancet 362 62-64.

Davis CG, Gallo ML \& Corvalan JR 1999 Transgenic mice as a source of fully human antibodies for the treatment of cancer. Cancer Metastasis Reviews 18 421-425.

Dawson NA, Guo C, Zak R, Dorsey B, Smoot J, Wong J \& Hussain A 2003 A phase II trial of ZD1839 in stage IV and recurrent renal cell carcinoma. Proceedings of the American Society of Clinical Oncology 22404 Abstract 1623.

Di Gennaro E, Barbarino M, Bruzzese F, De Lorenzo S, Caraglia M, Abbruzzese A, Avallone A, Comella P, Caponigro F, Pepe $\mathrm{S}$ et al. 2003 Critical role of both p27KIP1 and p21CIP1/ WAF1 in the antiproliferative effect of ZD1839 ('Iressa'), an epidermal growth factor receptor tyrosine kinase inhibitor, in head and neck squamous carcinoma cells. Journal of Cellular Physiology 195 139-150.

Douillard J-Y, Giaccone G, Horai T, Noda K, Vansteenkiste JF, Takata I, Gatzemeier U, Fukuoka M, Macleod A, Feyereislova A et al. 2002 Improvement in disease-related symptoms and quality of life in patients with advanced nonsmall-cell lung cancer (NSCLC) treated with ZD1839 ('Iressa') (IDEAL 1). Proceedings of the American Society of Clinical Oncology 21 299a. Abstract 1195.

Dragovich T, Patnaik A, Rowinsky EK, Karp D, Huberman M, Clinebell T, Hamilton M, Zitelli A, Nadler P \& Wood DL 2003 A phase I B trial of gemcitabine and erlotinib $\mathrm{HCl}$ in patients with advanced pancreatic adenocarcinoma and other potentially responsive malignancies. Proceedings of the American Society of Clinical Oncology 22223 Abstract 895.

Drucker BJ, Schwartz L, Marion S \& Motzer R 2002 Phase II trial of ZD1839 (Iressa), an EGF receptor inhibitor, in patients with advanced renal cell carcinoma. Proceedings of the American Society of Clinical Oncology 21 181a Abstract 720.

Earp HS III, Calvo BF \& Sartor CI 2003 The EGF receptor family - multiple roles in proliferation, differentiation, and neoplasia with an emphasis on HER4. Transactions of the American Clinical and Climatological Association 114 315-333.

Ennis BW, Lippman ME \& Dickson RB 1991 The EGF receptor system as a target for antitumor therapy. Cancer Investigation $9553-562$.

Fan Z, Shang BY, Lu Y, Chou JL \& Mendelsohn J 1997 Reciprocal changes in p27(Kip1) and p21(Cip1) in growth inhibition mediated by blockade or overstimulation of epidermal growth factor receptors. Clinical Cancer Research 3 1943-1948.

Figlin RA, Belldegrun AS, Crawford J, Lohner M, Roskos L, Yang X-D, Foon KA, Schwab G \& Weiner L 2002 ABXEGF, a fully human anti-epidermal growth factor receptor monoclonal antibody in patients with advanced cancer: phase I clinical results. Proceedings of the American Society of Clinical Oncology 21 10a Abstract 35.

Finkler N, Gordon A, Crozier M, Edwards R, Figueroa JGA, Hainsworth J, Irwin D, Silberman S, Allen L, Ferrante K et 
al. 2001 Phase 2 evaluation of OSI-774, a potent oral antagonist of the EGFR-TK in patients with advanced ovarian carcinoma. Proceedings of the American Society of Clinical Oncology 20 208a Abstract 831.

Fountzilas G, Pectasides D, Skarlos CV, Kalofonos HP, Papadimitriou C, Linardou H, Saridaki Z, Briasoulis E, Kosmidis P, Razis E et al. 2003 Paclitaxel, carboplatin and gefitinib ('Iressa', ZD1839) as first-line chemotherapy in patients with advanced breast cancer: a phase II study. Poster presented at: 26th San Antonio Breast Cancer Symposium. Poster 357.

Fukuoka M, Yano S, Giaccone G, Tamura T, Nakagawa K, Douillard JY, Nishiwaki Y, Vansteenkiste J, Kudoh S, Rischin D et al. 2003 Multi-institutional randomized phase ii trial of gefitinib for previously treated patients with advanced non-small-cell lung cancer. Journal of Clinical Oncology 21 2237-2246.

Gatzemeier U, Rosell R, Ramlau G, Robinet G, Szczesna A, Quoix E, Font A, Jimenez E, Mueser M \& Harstrick A 2003 Cetuximab (C225) in combination with cisplatin/vinorelbine vs cisplatin/vinorelbine alone in the first-line treatment of patients with epidermal growth factor receptor (EGFR)positive advanced non-small cell lung cancer (NSCLC). Proceedings of the American Society of Clinical Oncology 22 642 Abstract 2582.

Gatzemeier U, Pluzanska A, Szczesna A, Kaukel E, Roubec J, Brennscheidt U, De Rosa F, Mueller B \& von Pawel J 2004 Results of a phase III trial of erlotinib (OSI-774) combined with cisplatin and gemcitabine (GC) chemotherapy in advanced non-small cell lung cancer (NSCLC). Proceedings of the American Society of Clinical Oncology 23617 Abstract 7010.

Giaccone G, Johnson DH, Manegold C, Scagliotti GV, Rosell R, Wolf M, Rennie P, Ochs J, Averbuch S \& Fandi A 2002 A phase III clinical trial of ZD1839 ('Iressa') in combination with gemcitabine and cisplatin in chemotherapy-naive patients with advanced non-small-cell lung cancer (INTACT 1). Annals of Oncology 13 2. Abstract 40.

Giaccone G, Johnson D, Scagliotti GV, Manegold C, Rosell R, Rennie P, Wolf M, Averbuch S, Grous J \& Fandi A 2003 Results of a multivariate analysis of prognostic factors of overall survival of patients with advanced non-small cell lung cancer treated with gefitinib (ZD1839) in combination with platinum-based chemotherapy in two large phase III trials (INTACT 1 and 2). Proceedings of the American Society of Clinical Oncology 22627 Abstract 2522.

Goldstein NI, Prewett M, Zuklys K, Rockwell P \& Mendelsohn J 1995 Biological efficacy of a chimeric antibody to the epidermal growth factor receptor in a human tumor xenograft model. Clinical Cancer Research 1 1311-1318.

Grant S, Qiao L \& Dent P 2002 Roles of ERBB family receptor tyrosine kinases, and downstream signaling pathways, in the control of cell growth and survival. Frontiers in Bioscience 7 d376-d389.

Grunwald V \& Hidalgo M $2003 a$ Developing inhibitors of the epidermal growth factor receptor for cancer treatment. Journal of the National Cancer Institute 95 851-867.
Grunwald V \& Hidalgo M 2003b Development of the epidermal growth factor receptor inhibitor OSI-774. Seminars in Oncology 30 23-31.

Harari PM \& Huang S-M 2001 Radiation response modification following molecular inhibition of epidermal growth factor receptor signaling. Seminars in Radiation Oncology $\mathbf{1 1}$ 281-289.

Harari PM, Huang S-M, Herbst R \& Quon H 2003 Molecular targeting of the epidermal growth factor receptor in head and neck cancer. In Head and Neck Cancer: a Multidisciplinary Approach, pp 1001-1016. Eds Harrison LB, Sessions RB \& Hong WK. Philadelphia, PA, USA: Lippincott, Williams and Wilkins.

Herbst RS 2002 Targeted therapy in non-small-cell lung cancer. Oncology 16 19-24.

Herbst RS $2003 a$ Dose-comparative monotherapy trials of ZD1839 in previously treated non-small cell lung cancer patients. Seminars in Oncology 30 30-38.

Herbst RS 2003b Erlotinib (Tarceva): an update on the clinical trial program. Seminars in Oncology 30 34-46.

Herbst RS \& Hong WK 2002 IMC-C225, an anti-epidermal growth factor receptor monoclonal antibody for treatment of head and neck cancer. Seminars in Oncology 29 18-30.

Herbst RS \& Shin DM 2002 Monoclonal antibodies to target epidermal growth factor receptor-positive tumors: a new paradigm for cancer therapy. Cancer 94 1593-1611.

Herbst RS, Giaccone G, Schiller J, Miller V, Natale R, Rennie P, Ochs J, Fandi A, Grous J \& Johnson D 2003 Subset analyses of INTACT results for gefitinib (ZD1839) when combined with platinum-based chemotherapy for advanced non-small cell lung cancer. Proceedings of the American Society of Clinical Oncology 22627 Abstract 2523.

Herbst RS, Prager D, Hermann R, Miller V, Fehrenbacher L, Hoffman P, Johnson B, Sandler AB, Mass R \& Johnson DH 2004 TRIBUTE - A phase III trial of erlotinib HCI (OSI774) combined with carboplatin and paclitaxel (CP) chemotherapy in advanced non-small cell lung cancer (NSCLC). Proceedings of the American Society of Clinical Oncology 23617 Abstract 7011.

Hidalgo M, Siu LL, Nemunaitis J, Rizzo J, Hammond LA, Takimoto C, Eckhardt SG, Tolcher A, Britten CD, Denis L et al. 2001 Phase I and pharmacologic study of OSI-774, an epidermal growth factor receptor tyrosine kinase inhibitor, in patients with advanced solid malignancies. Journal of Clinical Oncology 19 3267-3279.

Hirata A, Ogawa S, Kometani T, Kuwano T, Naito S, Kuwano M \& Ono M 2002 ZD1839 (Iressa) induces antiangiogenic effects through inhibition of epidermal growth factor receptor tyrosine kinase. Cancer Research 62 2554-2560.

Huang SM \& Harari PM 1999 Epidermal growth factor receptor inhibition in cancer therapy: biology, rationale and preliminary clinical results. Investigational New Drugs 17 259-269.

Huang SM, Bock JM \& Harari PM 1999 Epidermal growth factor receptor blockade with C225 modulates proliferation, apoptosis, and radiosensitivity in squamous cell carcinomas of the head and neck. Cancer Research 59 1935-1940.

Iwata KK, Provoncha K \& Gibson N 2002 Inhibition of mutant EGFRvIII transformed cells by tyrosine kinase inhibitor OSI- 
774 (Tarceva). Proceedings of the American Society of Clinical Oncology 21 21a Abstract 79.

Johnson DH, Herbst R, Giaccone G, Schiller J, Natale RB, Miller V, Wolf M, Helton A, Averbuch S \& Grous J 2002 ZD1839 ('Iressa') in combination with paclitaxel \& carboplatin in chemotherapy-naive patients with advanced non-small-cell lung cancer (NSCLC): results from a phase III clinical trial (INTACT 2). Annals of Oncology 13127. Abstract 4680.

Jungbluth AA, Stockert E, Huang HJS, Collins VP, Coplan K, Iversen K, Kolb D, Johns TJ, Scott AM, Gullick WJ et al. 2003 A monoclonal antibody recognizing human cancers with amplification/overexpression of the human epidermal growth factor receptor. PNAS 100 639-644.

Karashima T, Sweeney P, Slaton JW, Kim SJ, Kedar D, Izawa JI, Fan Z, Pettaway C, Hicklin DJ, Shuin T et al. 2002 Inhibition of angiogenesis by the antiepidermal growth factor receptor antibody ImClone C225 in androgen-independent prostate cancer growing orthotopically in nude mice. Clinical Cancer Research 8 1253-1264.

Karp DD, Silbrman SL, Csudae R, Wirth F, Gaynes L, Posner M, Bubley G, Koon H, Bergman M, Huang M et al. 1999 Phase I dose escalation study of epidermal growth factor receptor (EGFR) tyrosine kinase (TK) inhibitor CP-358,774 in patients with advanced solid tumors. Proceedings of the American Society of Clinical Oncology 18 388a Abstract 1499

Kelly K, Hanna N, Rosenberg A, Bunn PA \& Needle MN 2003 A multicenter phase I/II study of cetuximab in combination with paclitaxel and carboplatin in untreated patients with stage IV non-small cell lung cancer. Proceedings of the American Society of Clinical Oncology 22644 Abstract 2592.

Kies MS, Arquette MA, Nabell L, Quin D, Shin D, Needle MN, Waksal H, Hong WK \& Herbst RS 2002 Final report of the efficacy and safety of the anti-epidermal growth factor antibody Erbitux (IMC-C225), in combination with cisplatin in patients with recurrent squamous cell carcinoma of the head and neck (SCCHN) refractory to cisplatin containing chemotherapy. Proceedings of the American Society of Clinical Oncology 21 232a Abstract 925.

Kim ES, Khuri FR \& Herbst RS 2001 Epidermal growth factor receptor biology (IMC-C225). Current Opinion in Oncology 13 506-513.

Kim ES, Mauer AM, Fossella FV, Jamison TA, Kies MS, Pisters KM, Glisson BS, Blumenschein GRJ, Zinner RG, Tran HT et al. 2002 A phase II study of erbitux (IMC-C225), an epidermal growth factor receptor (EGFR) blocking antibody, in combination with docetaxel in chemotherapy refractory/ resistant patients with advanced non-small cell lung cancer (NSCLC). Proceedings of the American Society of Clinical Oncology 21 293a Abstract 1168.

Kris MG, Natale RB, Herbst RS, Lynch TJJ, Prager D, Belani CP, Schiller JH, Kelly K, Spiridonidis C, Albain KS et al. 2002 A phase II trial of ZD1839 ('Iressa') in advanced nonsmall cell lung cancer (NSCLC) patients who had failed platinum- and docetaxel-based regimens (IDEAL 2). Proceedings of the American Society of Clinical Oncology 21 292a. Abstract 1166.

Kris MG, Natale RB, Herbst RS, Lynch TJ Jr, Prager D, Belani CP, Schiller JH, Kelly K, Spiridonidis H, Sandler A et al.
2003 Efficacy of gefitinib, an inhibitor of the epidermal growth factor receptor tyrosine kinase, in symptomatic patients with non-small cell lung cancer: a randomized trial. Journal of the American Medical Association 290 2149-2158.

Lynch DH \& Yang XD 2002 Therapeutic potential of ABXEGF: a fully human anti-epidermal growth factor receptor monoclonal antibody for cancer treatment. Seminars in Oncology 29 47-50.

Lynch TJ, Bell DW, Sordella R, Gurubhagavatula S, Okimoto RA, Brannigan BW, Harris PL, Haserlat SM, Supko JG, Haluska FG et al. 2004 Activating mutations in the epidermal growth factor receptor underlying responsiveness of nonsmall-cell lung cancer to gefitinib. New England Journal of Medicine 350 2129-2139.

Magne N, Fischel JL, Dubreuil A, Formento P, Poupon MF, Laurent-Puig P \& Milano G 2002 Influence of epidermal growth factor receptor (EGFR), p53 and intrinsic MAP kinase pathway status of tumour cells on the antiproliferative effect of ZD1839 ('Iressa'). British Journal of Cancer $\mathbf{8 6}$ 1518-1523.

Mendelsohn J 2001 The epidermal growth factor receptor as a target for cancer therapy. Endocrine-Related Cancer 8 3-9.

Mendelsohn J \& Baselga J 2003 Status of epidermal growth factor receptor antagonists in the biology and treatment of cancer. Journal of Clinical Oncology 21 2787-2799.

Meropol MJ, Berlin J, Hecht JR, Croghan GA, Patnaik A, Weiner LM, Sweed MF, Wiens BL, Caron D \& Visonneau S 2003 Multicenter study of ABX-EFR monotherapy in patients with metastatic colorectal cancer. Proceedings of the American Society of Clinical Oncology 22256 Abstract 1026.

Miller VA, Patel J, Shah N, Kris MG, Tyson L, Pizzo B, Zakowski M, Memoli N, Sandler A \& Johnson DH 2003 The epidermal growth factor receptor tyrosine kinase inhibitor erlotinib (OSI-774) shows promising activity in patients with bronchioloalveolar cell carcinoma (BAC): preliminary results of a phase II trial. Proceedings of the American Society of Clinical Oncology 22619 Abstract 2491.

Mishima K, Johns TG, Luwor RB, Scott AM, Stockert E, Jungbluth AA, Ji XD, Suvarna P, Voland JR, Old LJ et al. 2001 Growth suppression of intracranial xenografted glioblastomas overexpressing mutant epidermal growth factor receptors by systemic administration of monoclonal antibody $(\mathrm{mAb}) 806$, a novel monoclonal antibody directed to the receptor. Cancer Research 61 5349-5354.

Moulder SL, Yakes FM, Muthuswamy SK, Bianco R, Simpson JF \& Arteaga CL 2001 Epidermal growth factor receptor (HER1) tyrosine kinase inhibitor ZD1839 (Iressa) inhibits HER2/neu (erbB2)-overexpressing breast cancer cells in vitro and in vivo. Cancer Research 61 8887-8895.

Moyer JD, Barbacci EG, Iwata KK, Arnold L, Boman B, Cunningham A, DiOrio C, Doty J, Morin MJ, Moyer MP et al. 1997 Induction of apoptosis and cell cycle arrest by CP358,774 , an inhibitor of epidermal growth factor receptor tyrosine kinase. Cancer Research 57 4838-4848.

Naramura M, Gillies SD, Mendelsohn J, Reisfeld RA \& Mueller BM 1993 Therapeutic potential of chimeric and murine anti(epidermal growth factor receptor) antibodies in a metastasis model for human melanoma. Cancer Immunology and Immunotherapy 37 343-349. 
Needle MN 2002 Safety experience with IMC-C225, an antiepidermal growth factor receptor antibody. Seminars in Oncology 29 55-60.

Nicholson RI, Gee JM \& Harper ME 2001 EGFR and cancer prognosis. European Journal of Cancer 37 (Suppl 4) S9-S15.

Paez JG, Janne PA, Lee JC, Tracy S, Greulich H, Gabriel S, Herman P, Kaye FJ, Lindeman N, Boggon TJ et al. 2004 EGFR mutations in lung cancer: correlation with clinical response to gefitinib therapy. Science 304 1497-1500.

Perez-Soler R, Chachoua A, Huberman M, Karp D, Rigas J, Hammond L, Rowinsky E, Preston D, Ferrante KJ, Allen LF et al. $2001 \mathrm{~A}$ phase II trial of the epidermal growth factor receptor (EGFR) tyrosine kinase inhibitor OSI-774, following platinum-based chemotherapy, in patients (pts) with advanced, EGFR-expressing, non-small cell lung cancer (NSCLC). Proceedings of the American Society of Clinical Oncology 21 309a Abstract 1235.

Perrotte P, Matsumoto T, Inoue K, Kuniyasu H, Eve BY, Hicklin DJ, Radinsky R \& Dinney CP 1999 Anti-epidermal growth factor receptor antibody $\mathrm{C} 225$ inhibits angiogenesis in human transitional cell carcinoma growing orthotopically in nude mice. Clinical Cancer Research 5 257-265.

Pollack VA, Savage DM, Baker DA, Tsaparikos KE, Sloan DE, Moyer JD, Barbacci EG, Pustilnik LR, Smolarek TA, Davis JA et al. 1999 Inhibition of epidermal growth factor receptorassociated tyrosine phosphorylation in human carcinomas with CP-358,774: dynamics of receptor inhibition in situ and antitumor effects in athymic mice. Journal of Pharmacology and Experimental Therapeutics 291 739-748.

Prados M, Chang S, Burton A, Kapadia A, Rabbitt J, Page M, Federoff A, Kelly S \& Fyfe G 2003 Phase I study of OSI-774 alone or with temozolomide in patients with malignant glioma. Proceedings of the American Society of Clinical Oncology 2299 Abstract 394.

Prewett M, Rockwell P, Rockwell RF, Giorgio NA, Mendelsohn J, Scher HI \& Goldstein NI 1996 The biologic effects of C225, a chimeric monoclonal antibody to the EGFR, on human prostate carcinoma. Journal of Immunotherapy with Emphasis on Tumor Immunology 19 419-427.

Prewett M, Rothman M, Waksal H, Feldman M, Bander NH \& Hicklin DJ 1998 Mouse-human chimeric anti-epidermal growth factor receptor antibody C225 inhibits the growth of human renal cell carcinoma xenografts in nude mice. Clinical Cancer Research 4 2957-2966.

Prewett M, Overholser J, Hooper A \& Waksal HH 1999 Growth inhibition of human pancreatic carcinoma in vitro and in vivo by chimeric anti-EGF receptor monoclonal antibody C225.

Proceedings of the American Association for Cancer Research 40730 Abstract 4818.

Qu CK 2002 Role of the SHP-2 tyrosine phosphatase in cytokineinduced signaling and cellular response. Biochimica et Biophysica Acta 1592 297-301.

Ranson M, Hammond LA, Ferry D, Kris M, Tullo A, Murray PI, Miller V, Averbuch S, Ochs J, Morris C et al. 2002 ZD1839, a selective oral epidermal growth factor receptortyrosine kinase inhibitor, is well tolerated and active in patients with solid, malignant tumors: results of a phase I trial. Journal of Clinical Oncology 20 2240-2250.
Robert F, Ezekiel MP, Spencer SA, Meredith RF, Bonner JA, Khazaeli MB, Saleh MN, Carey D, LoBuglio AF, Wheeler RH et al. 2001 Phase I study of anti-epidermal growth factor receptor antibody cetuximab in combination with radiation therapy in patients with advanced head and neck cancer. Journal of Clinical Oncology 19 3234-3243.

Robert F, Blumenschein G, Dicke K, Tseng J, Saleh MN \& Needle M 2003 Phase IB/IIA study of anti-epidermal growth factor receptor antibody, cetuximab, in combination with gemcitabine/carboplatin in patients with advanced stage IV non-small cell lung cancer. Proceedings of the American Society of Clinical Oncology 22643 Abstract 2587.

Robertson JFR, Gutteridge E, Cheung KL, Owers R, Koehler M, Hamilton L, Gee J, Nicholson RI 2003 Gefitinib ('Iressa', ZD1839) is active in acquired tamoxifen (TAM)-resistant oestrogen receptor (ER)-positive and ER-negative breast cancer: results from a phase II study. Proceedings of the American Society of Clinical Oncology 227 Abstract 23.

Rosenberg AH, Loehrer PJ, Needle MN, Waksal H, Hollywood E, Ramos L \& Saltz LB 2002 Erbitux (IMC-C225) plus weekly irinotecan (CPT-11), fluorouracil (5FU) and leucovorin (LV) in colorectal cancer (CRC) that expresses the epidermal growth factor receptor (EGFR). Proceedings of the American Society of Clinical Oncology 21 135a Abstract 536.

Roskos L, Lohner M, Osborn K, Pasumarthi R, Lu H, Funelas C, Raie N, Yang X-D, Weiner L, Figlin RA et al. 2002 Low pharmacokinetic variability facilitates optimal dosing of ABX-EGF in cancer patients. Proceedings of the American Society of Clinical Oncology 21 91a Abstract 362.

Salomon DS, Brandt R, Ciardiello F \& Normanno N 1995 Epidermal growth factor-related peptides and their receptors in human malignancies. Critical Reviews in Oncology/ Hematology 19 183-232.

Saltz L, Rubin M, Hochster H, Tchekmeydian NS, Waksal H, Needle M \& LoBuglio A 2001 Cetuximab (IMC-C225) plus irinotecan (CPT-11) is active in CPT-11-refractory colorectal cancer (CRC) that expresses epidermal growth factor receptor (EGFR). Proceedings of the American Society of Clinical Oncology 20 3a Abstract 7.

Saltz L, Meropol NJ, Loehrer PJ, Waksal H, Needle MN \& Mayer RJ 2002 Single agent IMC-C225 (Erbitux(tm)) has activity in CPT-11-refractory colorectal cancer (CRC) that expresses the epidermal growth factor receptor (EGFR). Proceedings of the American Society of Clinical Oncology 21 127a Abstract 504.

Saltz L, Kies M, Abbruzzese JL, Azarnia N \& Needle M 2003 The presence and intensity of the cetuximab-induced acne-like rash predicts increased survival in studies across multiple malignancies. Proceedings of the American Society of Clinical Oncology 22204 Abstract 817.

Saul H 2003 27th ESMO Congress, Nice, 18-22 October 2002. Iressa disappoints in NSCLC. European Journal of Cancer 391.

Schoffski P, Lutz MP, Folprecht G, Beutel G, Seufferlein T, Marschner JP, Harstrick A \& Kohne CH 2002 Cetuximab (C225) plus irinotecan (CPT-11) plus infusional 5FU-folinic acid (FA) is safe and active in metastatic colorectal cancer (MCRC), that expresses epidermal growth factor receptor 
(EGFR). Proceedings of the American Society of Clinical Oncology 21 159a Abstract 633.

Schultz J 2003 Apparent adverse drug reactions prompt concern about Iressa. Journal of the National Cancer Institute $\mathbf{9 5}$ 577-579.

Schwartz G, Dutcher J, Vogelzang N, Gollob J, Thompson J, Bukowski RM, Figlin RA, Lohner M, Roskos L, Hwang CC et al. 2002 Phase 2 clinical trial evaluating the safety and effectiveness of ABX-EGF in renal cell cancer (RCC). Proceedings of the American Society of Clinical Oncology 21 Abstract 91.

Shepherd FA, Pereira J, Ciuleanu TE, Tan EH, Hirsh V, Thongprasert S, Bezjak A, Tu D, Santabarbara P \& Seymour L 2004 A randomized placebo-controlled trial of erlotinib in patients with advanced non-small cell lung cancer (NSCLC) following failure of 1 st line or 2 nd line chemotherapy. A National Cancer Institute of Canada Clinical Trials Group (NCIC CTG) trial. Proceedings of the American Society of Clinical Oncology 23. Abstract 7022.

Shin DM, Donato NJ, Perez-Soler R, Shin HJ, Wu JY, Zhang P, Lawhorn K, Khuri FR, Glisson BS, Myers J et al. 2001 Epidermal growth factor receptor-targeted therapy with C225 and cisplatin in patients with head and neck cancer. Clinical Cancer Research 7 1204-1213.

Sirotnak FM 2003 Studies with ZD1839 in preclinical models. Seminars in Oncology 30 12-20.

Sirotnak FM, Zakowski MF, Miller VA, Scher HI \& Kris MG 2000 Efficacy of cytotoxic agents against human tumor xenografts is markedly enhanced by coadministration of ZD1839 (Iressa), an inhibitor of EGFR tyrosine kinase.Clinical Cancer Research 6 4885-4892.

Sorkina T, Huang F, Beguinot L \& Sorkin A 2002 Effect of tyrosine kinase inhibitors on clathrin-coated pit recruitment and internalization of epidermal growth factor receptor. Journal of Biological Chemistry 277 27433-27441.

Soulieres D, Senzer NN, Vokes EE, Hidalgo M, Agarwala SS \& Siu LL 2004 Multicenter phase II study of erlotinib, an oral epidermal growth factor receptor tyrosine kinase inhibitor, in patients with recurrent or metastatic squamous cell cancer of the head and neck. Journal of Clinical Oncology 22 77-85.

Toyoda H, Komurasaki T, Uchida D \& Morimoto S 1997 Distribution of mRNA for human epiregulin, a differentially expressed member of the epidermal growth factor family. Biochemical Journal 326 69-75.

Van Laethem J-L, Raoul J-L, Mitry E, Brezault C, Husseini F, Cals L, Vedovato JC, Mueser MM \& Rougier P 2003 Cetuximab (C225) in combination with bi-weekly irinotecan (CPT-11), infusional 5-fluorouracil (5-FU), and folinic acid (FA) in patients with metastatic colorectal cancer (CRC) expressing the epidermal growth factor receptor (EGFR). Preliminary safety and efficacy results. Proceedings of the American Society of Clinical Oncology 22264 Abstract 1058.

Vega-Villegas E, Awada R, Mesia L Geoffrois L, Borel C, Humblet Y, Lopez-Poussa A, Hitt R, Amellal N \& Bourhis J 2003 A phase I study of cetuximab in combination with cisplatin or carboplatin and 5-FU in patients with recurrent or metastatic squamous cell carcinoma of the head and neck. Proceedings of the American Association for Cancer Research 22502 Abstract 2020.
Viens P, L'Homme C, Extra JM, Gladieff L, Kalla S \& Fabbro M 2003 A phase II trial to evaluate efficacy and safety of gefitinib (ZD1836) in patients with loco-regionally advanced or metastatic squamous cell carcinoma of the cervix.

Proceedings of the American Society of Clinical Oncology 22 456 Abstract 1833.

Viloria-Petit AM, Rak J, Hung MC, Rockwell P, Goldstein N, Fendly B \& Kerbel RS 1997 Neutralizing antibodies against epidermal growth factor and ErbB-2/neu receptor tyrosine kinases down-regulate vascular endothelial growth factor production by tumor cells in vitro and in vivo: angiogenic implications for signal transduction therapy of solid tumors. American Journal of Pathology 151 1523-1530.

Wang P, Fredlin P, Davis CG \& Yang X-D 2002 Therapeutic potential of ABX-EGF, a fully human anti-EGF receptor monoclonal antibody for the treatment of renal cell carcinoma. Proceedings of the American Society of Clinical Oncology 21 191a Abstract 761.

Wang P, Fredlin P, Davis CG \& Yang X-D 2003 Human antiEGF receptor monoclonal antibody ABX-EGF: a potential monotherapy for the treatment of prostate cancer.

Proceedings of the American Society of Clinical Oncology 22 Abstract 4525.

Watanabe T, Shintani A, Nakata M, Shing Y, Folkman J, Igarashi K \& Sasada R 1994 Recombinant human betacellulin. Molecular structure, biological activities, and receptor interaction. Journal of Biological Chemistry 269 9966-9973.

Wells A 1999 EGF receptor. International Journal of Biochemistry and Cell Biology 31 637-643.

Wiley HS 2003 Trafficking of the ErbB receptors and its influence on signaling. Experimental Cell Research 284 78-88.

Woodburn JR 1999 The epidermal growth factor receptor and its inhibition in cancer therapy. Pharmacology and Therapeutics 82 241-250.

Woodburn JR, Kendrew J, Fennell M \& Wakeling AE 2000 ZD1839 ('IRESSA') A selective epidermal growth factor receptor tyrosine kinase inhibitor (EGFR-TKI): inhibition of c-fos mRNA, an intermediate marker of EGFR activation, correlates with tumor growth inhibition. Proceedings of the American Association for Cancer Research 41402 Abstract 2552.

Yang XD, Jia XC, Corvalan JR, Wang P, Davis CG \& Jakobovits A 1999 Eradication of established tumors by a fully human monoclonal antibody to the epidermal growth factor receptor without concomitant chemotherapy. Cancer Research 59 1236-1243.

Yang XD, Jia XC, Corvalan JR, Wang P \& Davis CG 2001 Development of ABX-EGF, a fully human anti-EGF receptor monoclonal antibody, for cancer therapy. Critical Reviews in Oncology/Hematology 38 17-23.

Yarden Y 2001 The EGFR family and its ligands in human cancer: signalling mechanisms and therapeutic opportunities. European Journal of Cancer 37 (Suppl 4) S3-S8.

Yarden Y \& Sliwkowski MX 2001 Untangling the ErbB signalling network. Nature Reviews. Molecular Cell Biology 2 127-137. 